\title{
Marginalized Groups of Gelada (Theropithecus gelada) Living in and around the Highly Disturbed Mount Guna Community Conservation Area, Northwest Ethiopia
}

\author{
Hirpasa Teressa $\left(\mathbb{D},{ }^{1}\right.$ Hailu Minale, ${ }^{2}$ Solomon Birie, ${ }^{3}$ and Yismaw Alemayehu ${ }^{3}$ \\ ${ }^{1}$ Department of Biology, Wolkite University, Wolkite, Ethiopia \\ ${ }^{2}$ Department of Natural Resource Management, Debre Tabor University, Debra Tabor, Ethiopia \\ ${ }^{3}$ Department of Biology, Debre Tabor University, Debra Tabor, Ethiopia
}

Correspondence should be addressed to Hirpasa Teressa; hirpaifet100@gmail.com

Received 25 November 2020; Revised 6 September 2021; Accepted 13 October 2021; Published 8 November 2021

Academic Editor: Panos V. Petrakis

Copyright (c) 2021 Hirpasa Teressa et al. This is an open access article distributed under the Creative Commons Attribution License, which permits unrestricted use, distribution, and reproduction in any medium, provided the original work is properly cited.

\begin{abstract}
Gelada (Theropithecus gelada) is the only surviving primate of the genus Theropithecus that is endemic to Ethiopia. It adapted to live in afroalpine and subafroalpine ecosystems of the Ethiopian alpine. Although it is at risk of habitat loss due to agricultural expansion and deforestation, gelada has been classified as a least concern by the IUCN. Gelada has great importance as it represents the Ethiopian national treasure which brings tourists to the country. However, no proper gelada census has been carried out in and around Mount Guna (Mt. Guna). Therefore, the current study aimed to provide an accurate count of gelada individuals living in the study area. Total count along line transects was carried out from January 1-May 30, 2018, to estimate the population of gelada. According to the current result, gelada individuals counted from the entire sites of Mt. Guna were estimated to be 56. Forty-two gelada individuals were counted from outside the protected area, while 14 of them were from the protected area. There was a significant difference between gelada individuals counted from inside and outside the protected areas $(P=0.047)$. The ratio of age-sex of geladas also computed to be adult males: adult females: subadult males: subadult females: immature is 1: $3.12: 0.88: 1.25: 0.75$ for the total population. Furthermore, five groups of geladas were observed outside the Mt. Guna community conservation area at three sites, while only one group of geladas was identified from the protected area. Based on the current result, we recommend further research to study the population trend, fertility problems, and conservation mechanisms of geladas living within the agricultural land and human-gelada conflicts around Mt. Guna.
\end{abstract}

\section{Introduction}

Gelada (Theropithecus gelada) is the only surviving primate of the genus Theropithecus that is endemic to Ethiopia [1]. Currently, geladas occur only in a few areas of Ethiopian highlands, mostly the north of the Rift Valley in northern Ethiopia and rarely the south of the Rift Valley in Arsi Mountain [2]. Studies have estimated that the number of geladas is about $50,000-60,000$ in the wild, and their numbers are thought to be declining. In Ethiopian highlands, geladas are coming in contact with humans as local farmers expand their cultivation and livestock grazing to the areas once inhabited only by wildlife. In addition to this, due to their specialized diet (mainly grasses including Brachiaria comate, Cyperus erectus, Festuca abyssinica, and Festuca macrophylla), geladas are harshly affected by soil erosion, drought, and possibly even global warming $[3,4]$. Gelada is classified as nearly threatened in 2003. However, after some years, since it has a large range and is still abundant despite increasing threats to the species, it is listed as a least concern. Although the species is currently classified as a least concern, habitat loss due to agricultural expansion may affect the population of geladas [5].

Gelada is economically important as it is a fascinating mammal that brings many tourists to the country. It is an Ethiopian endemic genus representing a national treasure 
[6]. On the other hand, geladas have been blamed for raiding on cultivated lands. Studies showed that there is a major conflict between farmers and geladas in and around the Semien Mountains National Park (SMNP), Eastern Arsi, and South Wollo. The largest proportion of crop loss, mainly barley, was recorded in and around the SMNP [7]; crop loss including teff, maize, sorghum, barely, and wheat was reported from South Wollo [8], and significant crop (wheat, barley, maize, bean, and pea) loss was also identified in Eastern Arsi [9].

Mt. Guna, located in South Gondar Zone of the Amhara National Regional State, is known to be home to a number of endemic animals. Out of 30 mammals identified in Guna, 6 of them are endemic to Ethiopia. These 6 endemic mammals are Ethiopian highland hare, Lepus starcki, Ethiopian wolf, Canis simensis, gelada, Theropithecus gelada, Bailey's shrew, Crocidura baileyi, Abyssinian grass rat, Arvicanthis abyssinicus, and white-footed rat, Stenocephalemys albipes. Of these 6 endemic mammals, two of them are rodents and one is a primate [10].

Geladas have been known to exist in Mt. Guna for a long time. As cited in the work of Belste et al. [10], Abraham Marye has reported their number to be around 15 which shows the animal is locally endangered for extinction. However, according to the report by Belste et al. [10], the local community estimated that at least 100-200 individuals exist at two localities of Mt. Guna: Jib Washa and Molalie. From these reports, one can understand that there is a great difference between the populations of gelada in Mt. Guna within two years (2010-2012). Since geladas have low birth rate compared to other related primates [11], 15 individuals in 2010 have no reproductive potential to give 100-200 individuals in 2012 unless there might be an error in the methodology for one of the reports or both. Furthermore, currently, we have no accurate count of the number of geladas living in and around Mt. Guna and we have even less knowledge about the total numbers of geladas throughout Ethiopia. The knowledge of the accurate population of geladas, particularly in Mt. Guna and generally of Ethiopia, is important to determine whether their numbers are being maintained, declining, or increasing. In addition, establishing accurate numbers of the species is a critical criterion for conservation and management policies. Even though gelada has been known to exist in Mt. Guna, evidence shows that no proper and comprehensive gelada census has been carried out. Therefore, our aim was to provide an accurate count of gelada individuals living in Mt. Guna. Furthermore, the habitat distribution, age, and sex structure of the gelada groups was also provided.

\section{Materials and Methods}

2.1. Study Area. Mt. Guna is a recently legalized Community Conservation Area located in South Gondar Zone at a distance of $20 \mathrm{~km}$ from Debre Tabor town (capital of the zone) in the southeastern direction. The area is $129 \mathrm{~km}$ far from Bahir Dar, $699 \mathrm{~km}$ from Addis Ababa, and approximately $150 \mathrm{~km}$ south of the SMNP. Mt. Guna is located at $11^{\circ}$ $45^{\prime} \mathrm{N}, 38^{\circ} 15^{\prime} \mathrm{E}$ with an elevation ranging from $3200 \mathrm{~m}$ at the base to $4113 \mathrm{~m}$ at the peak $[10,12]$. There is $110 \mathrm{~km}^{2}$ of land above 3,400 $\mathrm{m}$, but no more than $40 \mathrm{~km}^{2}$ above 3,800 $\mathrm{m}$ [13]. Furthermore, according to Malcolm [14], a limited area of afroalpine is found in Mt. Guna.

The study area is characterized by moist agroclimatic zones that are locally known as moist "Dega" and "Wurch." It is the home of nationally and globally important biodiversities and forms part of the divide between the drainage basins of the Abay (Blue Nile River) and Tekeze rivers, and it is the origin of the Rib River, which flows into Lake Tana [10].

Mt. Guna is surrounded by six woredas (woreda- thirdlevel administration division of Ethiopia which is further subdivided into a number of kebeles), namely, Lay, Tach Gayint, Farta, East Este, Simada, and Dera (Figure 1). The economy of the people living in these woredas is mainly based on subsistence agriculture. They cultivate crops such as barley, wheat, bean, and potato, and they rear livestock including sheep, cattle, donkey, and horse. The vegetations of Mt. Guna include different grass species such as "Guassa" and tree species with many wild animals such as rodents, geladas, and jackals and different endemic and indigenous bird species. On the tip, the mountain has a giant lobelia tree which is known to be the unique characteristic to this ecosystem [10].

2.2. Methods of Data Collection. A cross-sectional study was carried out from 1 January-30 May 2018 around Mt. Guna. Data collection was conducted in the dry season due to unsuitable access to the area during rainy season. In the current study, line transect was used to estimate the population of gelada since it is the most common method to census nonhuman primate populations in the wild $[15,16]$. Monitoring of home range size and overlap in population was carried out prior to start counting [15-18]. In the course of monitoring, all gelada habitats and range sizes were identified and direct count was applied along the line transects. Scouts, local people, investigators, and wildlife experts were involved in the monitoring of gelada's home range sizes and population overlap and assessment of entire habitats.

At the beginning, all data collectors were trained on the methods of counting geladas. Then, data collectors together with investigators conducted a one-day observation of the study area, and data collectors were shown how to count geladas.

Before arranging line transects, all known gelada habitats in and around Mt. Guna were identified with the help of local people and scouts. Accordingly, four known gelada habitats, three outside and one inside the protected area, were identified from two kebeles (kebele- the smallest administrative unit of Ethiopia). Line transects were systematically laid across 4 identified gelada habitats (one inside and two outside the protected area), and direct total count was applied to estimate the numbers of all geladas and their groups. In addition to the four gelada habitats, 8 additional line transects (about $5 \mathrm{~km}$ long) were also systematically laid $1 \mathrm{~km}$ apart in the unprotected area (3 line transects) and 


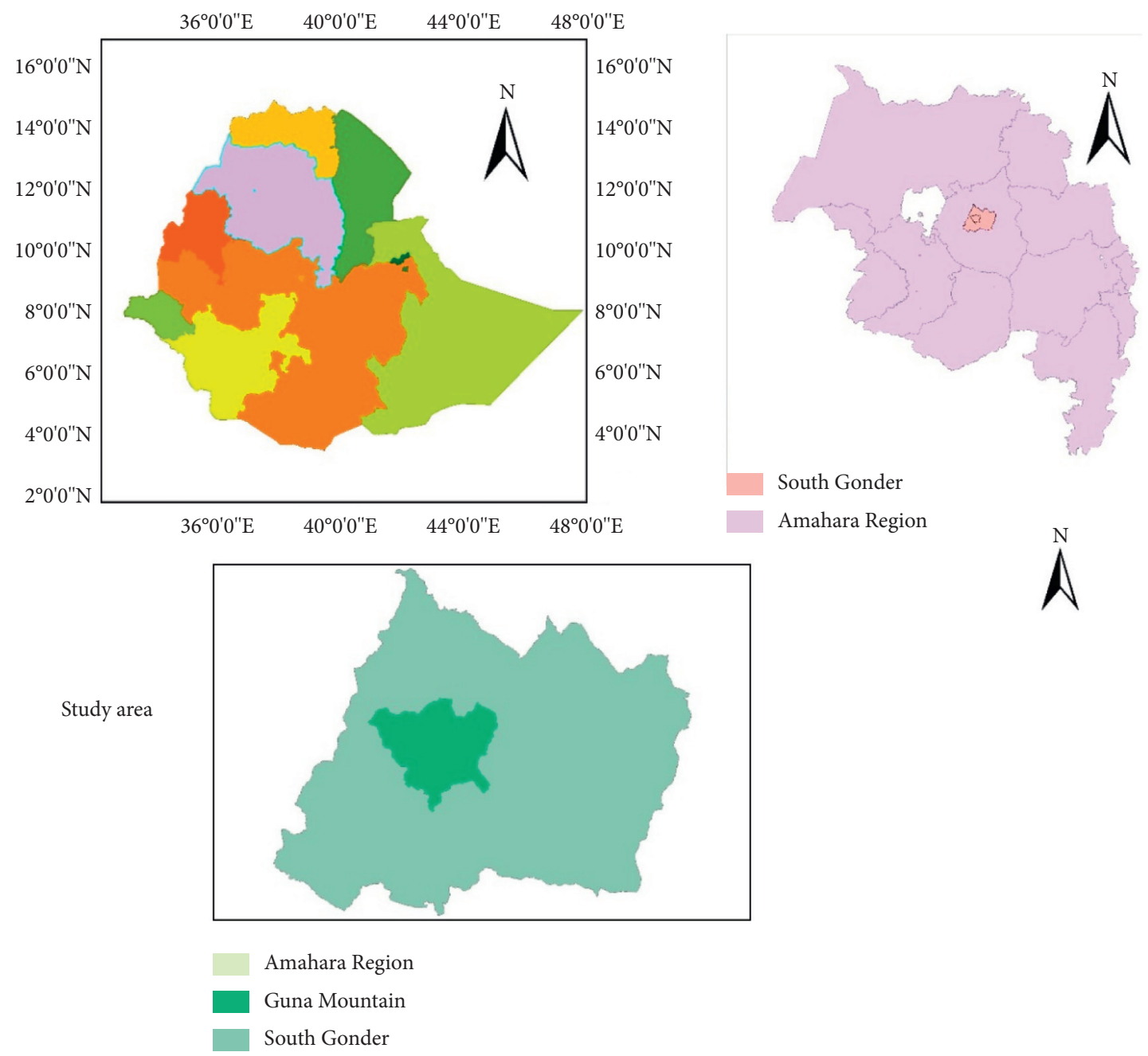

Figure 1: Map of the study area (Mt. Guna).

protected area (5 line transects) of $110 \mathrm{~km}^{2}$ of land to census if other gelada groups might be found. Three people were deployed to each of the 12 line transects to count all geladas found in and around Mt. Guna. All observers were told to record site/kebele, habitat type, age-sex structure, population number, and group number of geladas observed within $500 \mathrm{~m}$ right and left of the line transect. A binocular was used to count the animals at distance and for identification of age and sex. A digital camera was used to take the pictures. A total of 36 people were involved in the direct count: 3 wildlife experts from Debre Tabor town, 4 investigators from Debre Tabor University (authors), 2 undergraduate Debre Tabor University students, and 27 other data collectors from the surrounding kebeles. All line transects were addressed simultaneously, and gelada counts were conducted at the same time during morning hours (7: 00-11:00) when the animals were most active (foraging time).

Age-sex categories were structured as carried out by other authors. Accordingly, observers were asked to separate geladas into the following age-sex categories: adult males, adult females, subadult males, subadult females, and immature. Adult males were defined as geladas with visible manes and overall size about twice that of adult females, and adult females were estimated based on their body size. Subadult males were defined as males similar in size to adult females with the beginnings of a mane, and subadult females were estimated based on body size. All other smaller individuals were considered immature [19].

2.3. Data Analysis. All available data were organized and presented by using descriptive statistics including tables and pictures. Gelada's group and population numbers inside and outside the protected areas were presented on tables. In addition, the ratio of adult males: adult females: subadult males: subadult females: immature was calculated. Gelada abundance was computed by the abundance formula: 
Abundance $=\frac{\text { total number of individuals of the species in all the samplings }}{\text { No. of sampling units in which the species occur }}$.

One-way ANOVA on SPSS software version 20.0 was used to compare differences of the number of individual geladas between inside and outside the protected areas as well across the groups. A statistical value of 0.05 was taken as the significance level.

\section{Result and Discussion}

In the current study, the results of gelada count from the entire sites of Mt. Guna were estimated to be 56 . Out of the total 56 geladas, 3 gelada individuals were counted at Muhatitu, 24 at Molalie, 15 at Tirbgedel, and 14 at zingerogedel (Table 1). In addition, the abundance of geladas from these four sites was calculated to be 14 . In contrast to our study, Marye, as cited in the work of Belste et al. [10], estimated the number of geladas in Mt. Guna to be 15 and Belste et al. [10] estimated their number to be 100-200. Both population estimation of 2010 and 2012 is far from the current estimated number of geladas in Mt. Guna, or Marye might have only conducted population estimation for a group of geladas found at the top of Mt. Guna called Zingerogedel of the current study site. Furthermore, the current population of geladas counted in Mt. Guna is few in number when compared to the population of geladas living in other areas of the country. This existence of a small number of primates in a habitat shows habitat destruction due to intensive agricultural expansion, overgrazing, and other anthropogenic activities $[4,20]$. Such intensive agricultural activities were also observed in the development zone of Mt. Guna where a significant number of geladas live compared to the core zone (Figures 1 and 2). Unless agricultural activities are halted and entire habitats of Mt. Guna are conserved, such a condition may result in the local extinction of geladas in the near future. Moreover, this small number of geladas is highly marginalized since the habitat is far from the interaction of known nearby habitats with high population of gelada, SMNP (approximately $150 \mathrm{~km}$ north of Mt. Guna), and hence, the animal was already predicted to be locally endangered for extinction [10].

As identified in the SMNP, South Wollo, North Shoa, and other areas of the country $[4,8,21]$, geladas were also observed to live in a group in Mt. Guna. However, less number of individuals in a group that ranges from 3 to 15 consisting of an average of 9 individuals was counted in Mt. Guna. All age and sex groups were observed at Molalie, Tirbgedel, and Zingerogedel; however, a group of geladas counted at Muhatitu had only 3 adult male individuals (Table 1). Likewise, Dunbar [22] identified that young males leave their natal units as juvenile or subadult to join or form all-male groups. In such cases, all-male groups are more labile in their attachment to their natal groups and may spend a significant proportion of their time wandering alone or attached to an adjacent group. Moreover, such an occurrence of a small group in the area might be due to the absence of predators. In agreement to this, a study showed that the absence of predators provides an additional advantage for geladas to live in small reproductive units in their natural habitats [23] even though there were no female individuals in the current small group.

The age-sex category of geladas was also carried out for the current study although it might be difficult to compute and analyze population structures for such a small group of marginalized animals. The age-sex of the total population consists of $14.28 \%$ adult males, $44.64 \%$ adult females, $12.5 \%$ subadult males, $17.86 \%$ subadult females, and $10.71 \%$ immature (Table 2). The ratio of adult males: adult females: subadult males: subadult females: immature was $1: 3.12$ : $0.88: 1.25: 0.75$ for the total population of geladas in Mt. Guna. The current result revealed that high percentage (44.64\%) of adult females and low percentage (10.71) of immature geladas occur in Mt. Guna. However, this ratio contrasts with that of gelada groups studied in and around the SMNP which is $1: 0.58: 3: 1.29: 2.78$ [6]. In our study, the ratio of adult male: adult female is $1: 3.12$ (high number of adult females) which gives hope to having high reproductive potential. On the other hand, the ratio of immature: adults males was $0.75: 1.0$. The least abundance of infant population in the group shows that the population of geladas in Mt. Guna is not increasing. This might be due to the presence of aged adult females in the group, or there might be other reproductive problems such as the absence of suitable habitat conditions. The abovementioned ratio contrasts with the studies conducted around the SMNP and South Wollo that had a considerably high infant population showing the number of geladas is increasing [8].

As presented in Table 3, geladas were counted from two kebeles, namely, Moksh (outside the protected area) and Guna gedeba (inside the protected area), in which a higher number $(n=42)$ of gelada individuals was from outside compared to that from inside the protected area $(n=14)$. There was a significant difference between the number of gelada individuals counted from these two localities ( $\mathrm{df}=1, P=0.047)$. In contrast to the fact that animals are more abundant in the protected area than the unprotected one, the current study identified a relatively high number of gelada individuals from around the agricultural land (outside the protected area). This might be due to different reasons: the area has been conserved recently ( 2 years) and still under anthropogenic pressure; relatively more availability of food and water adjacent to the agricultural land; and existence of different mountain cliffs down the subafroalpine ecosystem (Figure 2). Such habitat preference of geladas has been reported from other areas of the country [21].

Five groups of geladas were observed outside the Mt. Guna community conservation area (within the agricultural land) at three sites called Muhatitu, Molalie, and Tirbgedel (Table 3). However, only one group of geladas was observed inside the protected area at the tip of Mt. Guna (Figure 3). There was no significant difference among 
TABLE 1: Total number of geladas counted in each site with different age and sex groups.

\begin{tabular}{|c|c|c|c|c|c|c|}
\hline Area name & Adult males & Adult females & Subadult males & Subadult males & Immature & Total \\
\hline Muhatitu & 3 & 0 & 0 & 0 & 0 & 3 \\
\hline Molalie & 3 & 12 & 3 & 5 & 1 & 24 \\
\hline Tirbgedel & 1 & 6 & 2 & 3 & 3 & 15 \\
\hline Zingerogedel & 1 & 7 & 2 & 2 & 2 & 14 \\
\hline
\end{tabular}

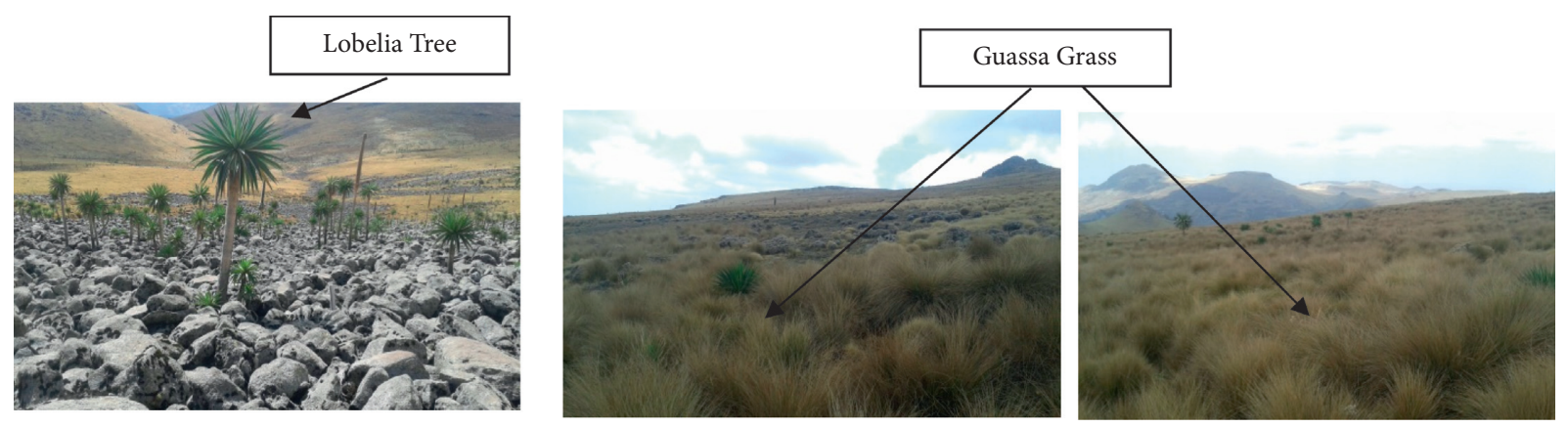

Figure 2: Mount Guna Community Conservation Area (photos captured by the author).

TABLE 2: Total number of geladas counted in Mt. Guna with respect to age and sex groups.

\begin{tabular}{lccccc}
\hline Area name & Adult males & Adult females & Subadult males & Subadult females & Immature \\
\hline Total no. & 8 & 25 & 7 & 10 & 6 \\
Percentage & 14.28 & 44.64 & 12.5 & 17.86 \\
Age-sex ratio & $1:$ & $3.12:$ & $0.88:$ & $1.25:$ & 0.71 \\
\hline
\end{tabular}

TABLE 3: Site, kebele, and total group number of Geladas in Mt. Guna.

\begin{tabular}{lccc}
\hline Localities & Kebeles/site & Number of groups & No. of individuals in a group \\
\hline & Muhatitu (Moksh) & 1 & 3 \\
Outside the protected area & Molalie (Moksh) & 3 & 24 \\
& Tirbgedel (Moksh) & 1 & 15 \\
& Total & 5 & 42 \\
\hline \multirow{2}{*}{ Inside the protected area } & Zingerogedel (Guna gedeba) & 1 & 14 \\
& Total & 1 & 14 \\
\hline
\end{tabular}

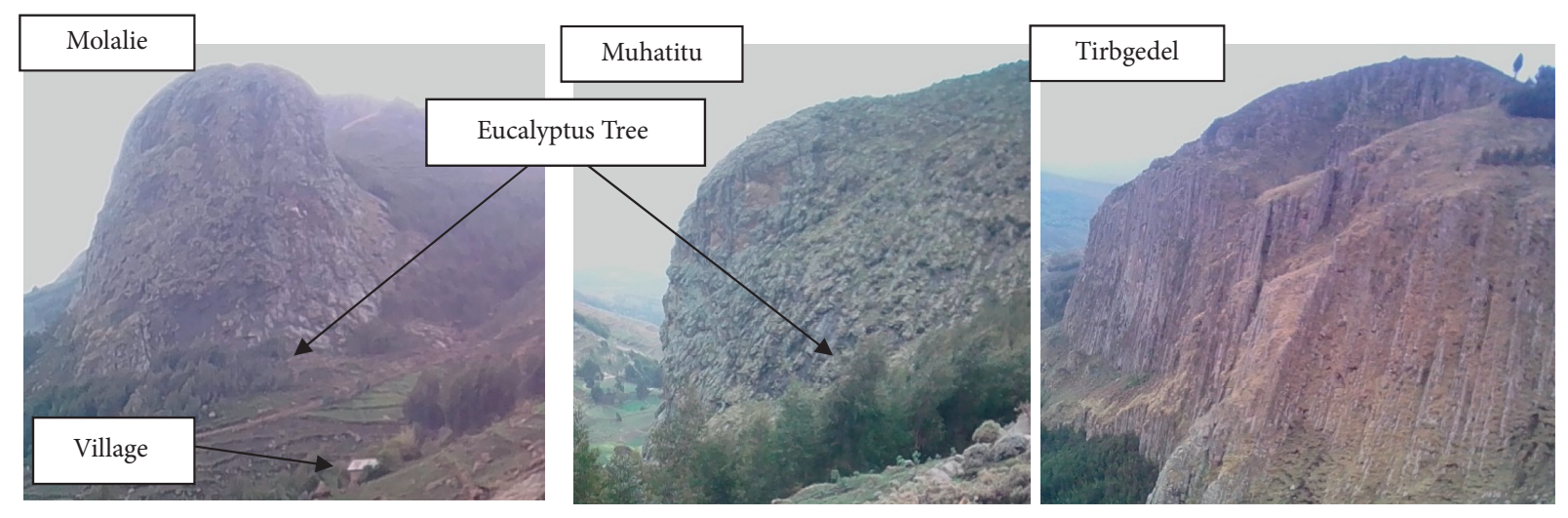

FIGURE 3: Gelada habitats outside the protected area (photos captured by data collector). 


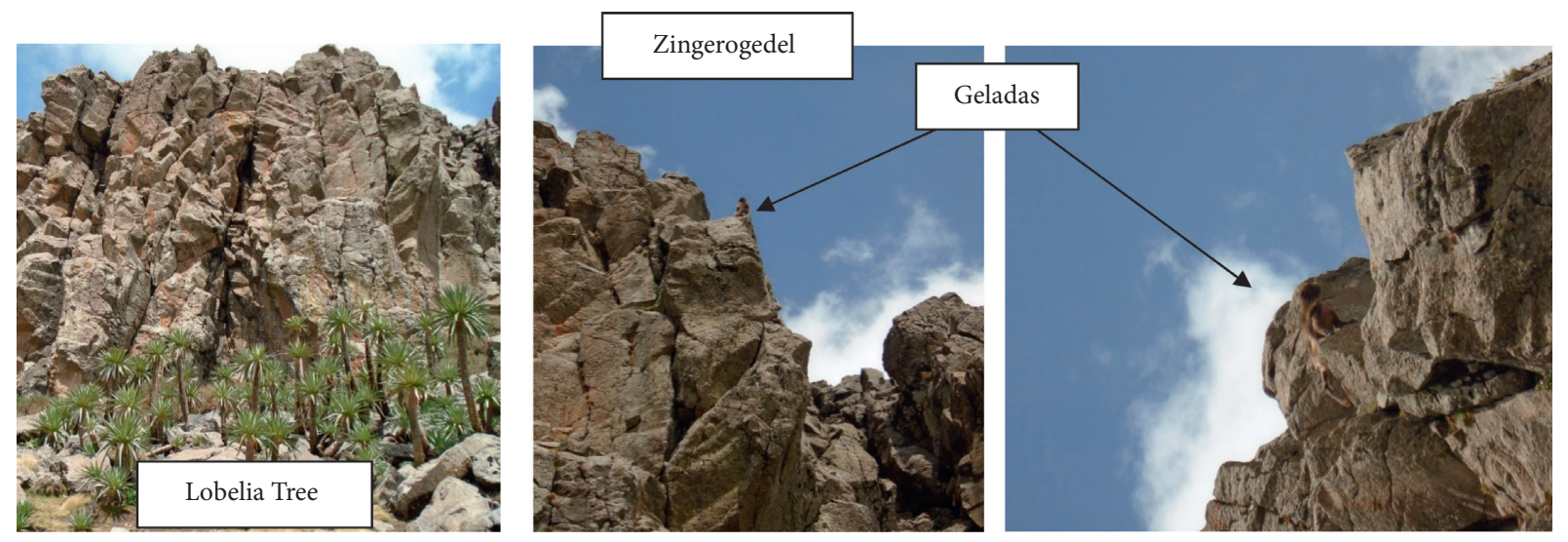

FIgURE 4: Geladas and gelada habitat inside the protected area (photos captured by the author).
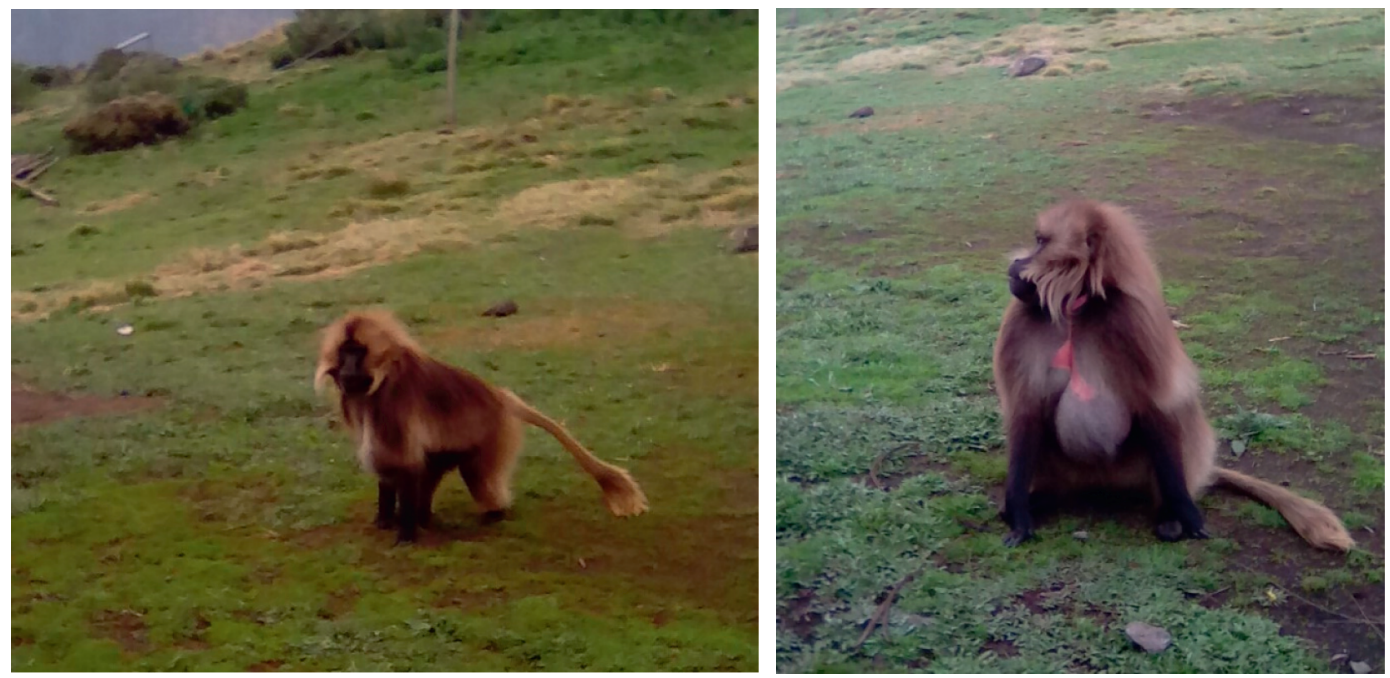

Figure 5: Geladas, photos captured at Semien Mountains National Park by the author.

the number of gelada individuals across the groups $(\mathrm{df}=3$, $P=0.225$ ). Out of the five groups, three of them were observed at the Molalie site. These three sites are found within the development zone (the zone where agricultural activities are carried out). This might be due to human encroachment into geladas' habitats as observed in Semien Mountains [6]. In such an agricultural land, geladas were observed to feed on cultivated crops leading to conflict with the local people [7]. Furthermore, a study revealed that geladas are known to eat leaves, roots, tubers, stems, seeds, grains, nuts, fruit, and flowers other than grass. As a result, geladas have been blamed for raiding on cultivated lands [7-9]. The single group observed at the tip of Mt. Guna might live safely in the protected area (Figures 4 and 3) since it is far from the disturbance of local farmers (development zone) because of overgrazing, and habitat destruction in the core zone has been inhibited by the local government (Mt. Guna Community Conservation Area Office) since 2016. Such a single group and small number of gelada occurrence inside the protected area are rare and in contrast to other reports [24].
In this study, geladas' pictures and habitats both inside and outside the protected areas were tried to be captured. However, geladas are not clearly visible on the picture due to inadaptability of geladas to be near people and unavailability of a high-quality camera that can take photographs from distance. The clear picture of geladas was taken from the SMNP where geladas are adapted to be very near tourists (Figure 5). As tried to present on the following photos (Figures 2 and 3), geladas inhabit highland areas bordered by cliffs. The gelada habitat inside the protected area is characterized by a rocky area surrounded by grassland which is similar to habitats reported from other areas. They were also observed to occur in the cultivated land outside the protected area as reported by other authors [25-28]. The mountain cliffs of gelada habitats outside the protected area which contain high population of geladas (42 gelada individuals out of 56) are surrounded by agricultural lands. A study showed that agricultural expansion is one of the major threats to geladas [5] although the area is relatively supporting a high number of geladas in the current study. 


\section{Conclusions}

In the present study, a small number of geladas accounting to 56 individuals in six groups was counted in and around the Mt. Guna community conservation area. Out of 56 gelada population and six groups, 42 individuals and five groups are found outside the protected area within the agricultural land. Furthermore, it has been identified that a marginalized population of gelada inhabits the highly disturbed afroalpine and subafroalpine ecosystem in Mt. Guna. Such a marginalized small number of primates in highly disturbed ecosystems may eventually lead to the local extinction of the animal. Based on the current result, future counts using the same method should be carried out in subsequent years to determine the population trend of geladas in Mt. Guna since most of them are prone to anthropogenic disturbances. Furthermore, the high population living within the agricultural land needs more conservationists' attention, and human-gelada conflict should be assessed.

\section{Data Availability}

All data used to support the results of the study have been included in the manuscript.

\section{Conflicts of Interest}

The authors declare no conflicts of interest.

\section{Acknowledgments}

The authors would like to thank Debre Tabor University for granting fund to conduct the current study. Furthermore, they would also like to thank the Biodiversity Conservation Office of South Gondar Zone for giving them permission to study wildlife in Mt. Guna. Finally, they thank the scouts of the Guna Community Conservation Area and local people for helping them in data collection.

\section{References}

[1] R. I. M. Dunbar, "The social ecology of gelada baboon," Ecological Aspects of Social Evolution: Birds and Mammals, vol. 33, pp. 332-351, 1986.

[2] A. Mori and G. Belay, "The distribution of baboon species and a new population of gelada baboons along the wabi-shebeli river, Ethiopia," Primates, vol. 31, no. 4, pp. 495-508, 1990.

[3] A. Kassahun, B. Afework, and M. Addisu, "Daily activity, feeding ecology and habitat association of Gelada baboon (Theropithecus gelada) around Debre-Libanos, Northwest Shewa Zone, Ethiopia," International Journal of Biodiversity and Conservation, vol. 9, no. 6, pp. 232-238, 2017.

[4] K. A. Zewdu, A Comparative Study on the Behavioural Ecology and Conservation of the Southern Gelada (Theropithecus gelada Obscurus) in and Around Borena Sayint National Park, Ethiopia, A Dissertation Submitted in Partial Fulfillment of the Requirements for the Degree of Doctor of Philosophy (PhD) in Ecological and Systematic Zoology in the Department of Zoological Sciences, Addis Ababa University, Addis Ababa, Ethiopia, 2018.
[5] S. Gippoliti and C. Hunter, Theropithecus gelada, In: IUCN 2010. IUCN Red List of Threatened Species, 2008.

[6] J. Beehner, G. Bergman, and C. McCann, "Population estimate for geladas (Theropithecus gelada) living in and around the simien mountains national Park, Ethiopia," Sinet: Ethiopian Journal of Science, vol. 30, pp. 149-154, 2007.

[7] Y. Mesele, B. Afework, and T. Zelealem, "Human-gelada baboon conflict in and around the simian mountains national Park, Ethiopia," African Journal of Ecology, vol. 47, pp. 276282, 2008.

[8] A. Yonatan, "Population status, distribution and ecology of gelada baboon (Theropithecus gelada) in azwa and arego, South Wollo, dessie, Ethiopia," A Thesis Submitted to the School of Graduate Studies of Addis Ababa University in Partial Fulfillment of the Requirements for the Degree of Master of Science in Biology, Addis Ababa University, Addis Ababa, Ethiopia, 2009.

[9] A. Kelil, Activity Patterns and Feeding Ecology of the Gelada Baboon (theropithecus Gelada Arsi) and Human-Gelada Conflicts in Amigna, Eastern Arsi, Ethiopia, Dissertation Submitted in Partial Fulfilment for the Requirements for the Degree of Doctor of Philosophy in Ecological and Systematic Zoology, Addis Ababa University, Addis Ababa, Ethiopia, 2018.

[10] F. Belste, H. Yosef, A. Birhanemeskel, K. Asmamaw, A. Yeshanew, and A. Getasew, Socioeconomic Situation, Tourism Potentials and Biodiversities Study Report for Mount Guna Proposed Community Conservation Area, Amhara National Regional State Bureau of Culture, Tourism and Parks Development in Collaboration with Organization for Rehabilitation and Development in Amhara, Amhara, Ethiopia, 2012.

[11] R. I. M. Dunbar, "Demographic and life history variables of a population of gelada Baboons (Theropithecus gelada)," Journal of Animal Ecology, vol. 49, no. 2, pp. 485-506, 1980.

[12] Organization for Rehabilitation and Development in Amhara (ORDA), CEPF Final Project Completion Report, Bahir Dar, Bahir Dar, Ethiopia, 2017.

[13] C. Sillero-Zubiri and D. W. Macdonald, The Ethiopian Wolf: Status Survey and Conservation Action Plan, IUCN/ SSC Specialist Group, Gland and Cambridge, England, 1997.

[14] J. R. Malcolm, "The range and status of the Simien fox (Canis simensis)," in Proceedings of Helsinki Meeting on Endangered Canids, IUCN/SSC Canid Specialist Group, pp. 19-27, Oxford, England, 1982.

[15] W. Y. Brockelman and R. Ali, "Methods of surveying and sampling forest primate populations," in Primate Conservation in the Tropical Rain Forest, C. W. Marsh and R. A. Mittermeier, Eds., pp. 23-62, Alan R. Liss, New York, NY, USA, 1987.

[16] P. J. Fashing and M. Cords, "Diurnal primate densities and biomass in the Kakamega Forest: an evaluation of census methods and a comparison with other forests," American Journal of Primatology, vol. 50, no. 2, pp. 139-152, 2000.

[17] C. Chapman, L. M. Fedigan, and L. Fedigan, "A comparison of transect methods of estimating population densities of Costa Rican primates," Brenesia, vol. 30, pp. 67-80, 1988.

[18] G. H. Whitesides, J. F. Oates, S. M. Green, and R. P. Kluberdanz, "Estimating primate densities from transects in a west african rain forest: a comparison of techniques," Journal of Animal Ecology, vol. 57, no. 2, pp. 345-367, 1988.

[19] J. Van Hooff, Macaques and Grzimek's Encycolpedia of Mammals, pp. 208-286, McGraw-Hill Press, New York, NY, USA, 1990. 
[20] K. Zewdu, B. Gurja, and A. Afework, "Population size, group composition and behevioural ecology of geladas (Thercopithicus geleda) and human-gelada conflict in Wonchit Valley, Ethiopia," Pakistan Journal of Biological Sciences, vol. 16, pp. 1248-1259, 2013.

[21] G. Birhanu and Y. Mesele, "Population structure and habitat use of gelada baboon (Theropithecus gelada) in Wof-Washa Forest (Gosh-Meda Area), Central Ethiopia," Journal of Ecology and Environment, vol. 42, no. 35, 2018.

[22] R. Dunbar and P Dunbar, "Social dynamics of gelada baboons," Contributions to Primatology, vol. 6, pp. 1-157, 1975.

[23] D. Ejigu and Afework Bekele, "Population structure and group size of geladas (Theropithecus gelada) at chenek, simien mountains national Park, Ethiopia," African Journal of Ecology, vol. 55, no. 4, 2017.

[24] J. Beehner, G. Berhanu, T. J. Bergman, and M. C. Cann, "Population estimate for gelada (Theropithecus gelada) living in and around the simien mountains national Park, Ethiopia," Ethiopian Journal of Science, vol. 3, pp. 1-5, 2008.

[25] J. H. Crook and P. Aldrich-Blake, "Ecological and behavioural contrasts between sympatric ground dwelling primates in Ethiopia," Folia Primatologica, vol. 8, no. 3-4, pp. 192-227, 1968.

[26] R. I. M. Dunbar, The Gelada Baboon: Status and Conservation, Primate Conservation, pp. 342-355, Academic Press, London, England, 1977b.

[27] D. W. Yalden and M. J. Largen, "The endemic mammals of Ethiopia,” Mammal Review, vol. 22, no. 3-4, pp. 115-150, 1992.

[28] T. Iwamoto, The Ecology of Theropithecus gelada, the Rise and Fall of a Primate Genus, Cambridge Univrsity Press, Cambridge, England, pp. 441-452, 1993. 